\title{
Intercultural Sensitivity Among Undergraduate University Students in Ethiopia
}

\author{
Ashebir Demeke Gebretsadik ${ }^{1^{*}} \quad$ Belay Tefera Kibret $^{2}$ \\ 1.Madda Walabu University, College of Education and Behavioral Studies, \\ Department of Psychology, Bale Robe, Ethiopia \\ 2.Addis Ababa University, College of Education and Behavioral Studies, \\ School of Psychology, Addis Ababa, Ethiopia
}

\begin{abstract}
Nowadays with the globalization of economy, increasing social mobility, rapid development of technology and the emergence of cultural diversity, intercultural human contact at both individual and organizational levels become increasing. The wide-ranged expansion of human contacts on the one hand and the cultural diversity on the other hand calls for people's sensitivity to cultural diversity. The purpose of this study was to investigate the status intercultural sensitivity and related factors among university students in Ethiopia. To attain the objective of the study cross sectional research design was employed. A total of 771 participants (484 males and 287 females) were sampled from four government universities. The adapted measuring scale was Intercultural Sensitivity Scale (Chen \& Starosta, 2000). The combinations of multistage cluster sampling, stratified simple random sampling, simple random sampling and purposive sampling procedures were employed to select the sample participants. The data were analyzed using Descriptive Statistical Measures (Mean, SD, Quartile \& Percentile Scores), Frequency percentage, Chi-square, independent-t test and one-way ANOVA. The findings of the study revealed that the target group university students were labelled at higher level of intercultural sensitivity status. Furthermore, the findings revealed significant mean difference on intercultural sensitivity due to sex, place grown up and different batches of university students. However, there was no significant difference on intercultural sensitivity score between mono and mixed ethnic background participants. Finally, implications and recommendations were forwarded.
\end{abstract}

Keywords: Intercultural Sensitivity, Cultural Diversity, Status, University Students

DOI: $10.7176 /$ RHSS/10-13-04

Publication date:July $31^{\text {st }} 2020$

\section{Introduction}

Some authorities use intercultural competence and intercultural sensitivity interchangeably. According to Chen and Starosta (2003) intercultural competence is "the ability to acknowledge, respect, tolerate, and integrate cultural differences that qualifies one for enlightened global citizenship" (p. 344). According to them, intercultural awareness, intercultural adroitness, and intercultural sensitivity constitute intercultural competence. Intercultural awareness means understanding cultural facets in the communication process. Intercultural adroitness refers to effective behavioural skills in intercultural interactions. Intercultural sensitivity is emotional readiness in intercultural interactions combined with understanding, respect, and tolerance (Chen \& Starosta, 2003). These three qualities are overlapping and mutually affect each other.

To be effective in another culture, people must be interested in other cultures, be sensitive enough to become aware of cultural differences, and then also be willing to adjust their behaviour as an indication of respect for the people of other cultures (Chen, 2010). They further stated that intercultural sensitivity is the core quality in intercultural competence, while other characteristics are peripheral indicators.

Furthermore, Bennett (1993) regards intercultural sensitivity as:

Specifically, we are interested in the way people construe cultural difference and in the varying kinds of experience that accompany different constructions. This experience is termed 'intercultural sensitivity,' and it is assumed that such sensitivity can be described in developmental terms better than as a collection of specific behaviours.(p. 24).

The popular and extensively mentioned theory of intercultural sensitivity development is that "the Developmental Model of Intercultural Sensitivity (DMIS)" which was introduced by Bennett (1986). The model was developed with a grounded theory approach (Strauss \& Corbin, 1990), which involves using theoretical concepts to explain a pattern that emerges from systematic observations. The model demonstrates how encounters with diverse individuals help to increase one's intercultural competence.

The main purpose of the Bennett's intercultural sensitivity model is to explain an individual's intercultural sensitivity levels associated with his/her worldview structure regarding cultural differences. The model is underpinned by the assumption that "as one's experience of cultural difference becomes more sophisticated, one's competence in intercultural relations potentially increases" (Bennett, 1998). In other words, the development of intercultural sensitivity, Bennett believes, is tightly related to one's subjective intercultural 
experience and intercultural competence. Furthermore, the DMIS may identify appropriate training, teaching, or coaching for developing intercultural sensitivity.

There are six stages in the DMIS, which relate to what happens to an individual with regard to cognitive, affective and behavioural development in response to cultural differences. The first three stages in DMIS are ethnocentric, which means one's personal culture is central to reality and the last three stages are ethnorelative, which mean that one's own culture is experienced in the perspective of other cultures. The following are the six stages on the DMIS continuum (Bennett, 1998):

1. Denial:-takes place when an individual is physically or socially isolated from contact with people who are culturally different. Individuals who have this viewpoint believe that their cultural reality is irrefutable. May sometimes it accompanied by attribution of deficiency in intelligence or personality to culturally deviant behaviour. There is tendency to dehumanize outsiders.

2. Defense: - occurs when individuals recognize difference between dissimilar cultures. However, they adopt an "us or them" mentality during this stage and feel that the group to which they belong is superior to others. People at this position are more openly threatened by cultural difference and more likely to be acting aggressively against it.

3. Minimization: - takes place when individuals in a cultural group trivialize other cultures and feel that all cultural groups are the same. People recognize superficial cultural differences in food, customs, etc..., but they emphasize human similarity in physical structure, psychological needs, and/or assumed adherence to universal values. People at this position are likely to assume that they are no longer ethnocentric, and they tend to overestimate their tolerance while underestimating the effect (e.g. "privilege") of their own culture. People at this stage believe that the behaviours of others should match their cultural expectations.

4. Acceptance: - is the recognition of different world views. At this stage, the individual is accepting of the behaviours and values of individuals from different cultures, although he or she may still view other cultures in a negative way.

5. Adaptation to difference - occurs when the individual is able to look at a situation through a different cultural lens. The individual may also change his/her behaviour to communicate more effectively with individuals from different cultures. Here effective use of empathy or frame of reference shifting, to understand and be understood across cultural boundaries.

6. Integration of cultural difference: - It allows the person to transfer in and out of different cultural worldviews. People at this position have a definition of self that is "marginal" (not central) to any particular culture, allowing this individual to shift rather smoothly from one cultural worldview to another. The individual can evaluate situations and events in a cultural context.

Ethiopia is inhabited nearly by 80 ethnic groups with over 200 dialects and composed of several ethnolinguistic communities with different histories, languages, and cultures. (CSA, 2008). Regardless of their diverse demographic and historical origins and with several points of contacts over the centuries, by and large, the ethnic groups have experienced inter-marriage, interdependency, attend similar religions and co-exist peacefully (Habtamu, Hallahmi \& Abbink, 2001) and have co-existed and continue to exist as nations among nations (Lubo, 2012).

However, in past and these days Ethiopia has faced relevant actors to untangle the myriad ethnic, political and religious interactions and conflicts have blown up among its citizens at different periods (Lubo, 2012; Asebe, 2007; Tilahun, 2007; Vaughan, 2003). The occasional interethnic conflicts which have occurred in some parts of the country, range from simple exchanges of words and insults to serious incidents that have escalated to certain severe conditions, such as burning of houses and farms, blood-shedding fights, and killing of members of other ethnic groups (Habtamu, Hallahmi \& Abbink, 2001).

To address the rights of ethnic groups and resolve deep rooted inter ethnic conflicts in the country beginning with the TPLF-led national conference in 1991, which set up a framework of the transitional government, EPRDF has restructured a political system in the country through a policy of "Ethnic Federalism" (Asefa, 1998). In ethnically divided countries, the hope is that political recognition of cultural and ethnic pluralism through federalism reduces ethnic tensions and conflicts (Fleiner, 2000).

Residential colleges and universities provide many students with an opportunity to experiment with new ideas, new relationships, and new roles. Peer influences play a normative role in this development, and students are able to explore options and possibilities before making permanent adult commitments (Pascarella \& Terenzini, 1991). Higher education is especially influential when its social milieu is different from students' home and community background and when it is diverse and complex enough to encourage intellectual experimentation and recognition of varied future possibilities. In fact modern institutions of higher education are expected to be beacons for harmony, bridging ethnic differences and promoting an atmosphere of reason, inquiry and collegiality (Blum, 2010). Moreover these higher institutions are deemed to address the teaching and learning of diversity by creating an environment that allows positive interaction among students from different ethnicities and backgrounds. Likewise, as declared on Higher Education Proclamation of Ethiopia (proclamation 
No. 650/2009), one of the objectives of higher education in Ethiopia is to promote democratic culture and uphold multicultural community life (FDRE, 2009). Phinney (1996) also assert that exposure to university programs may offer an opportunities of intellectual framework for understanding the historical, psychological, and sociological foundations of multiculturalism, prejudice, cultural and interethnic conflicts.

Nevertheless, sometimes unwise exposure to ethnic diversity in higher learning educations brings experience of ethnic prejudices, cultural ethnocentrism, feeling of distrust and intergroup conflicts. This is true that these days and in the past, in universities in Ethiopia, it has become common news to hear that students of one ethnic group are being in clashed with students from another ethnic group or other ethnic groups especially between those from the dominant ethnic groups such as Oromo, Amhara and Tigray (Abera H., 2010; Abera T., 2010; Asefa, 2009; Tilahun, 2007). Accordingly, the objective of this study was to investigate the status intercultural sensitivity and related factors among university students in Ethiopia.

\section{Research Questions}

1. What is the intercultural sensitivity status of Ethiopian university students?

2. Is there a significant mean difference in intercultural sensitivity score among university students in Ethiopia due to sex, ethnic background, place where grown up, and year in university (batches)?

\section{Materials and Methods}

To achieve the purpose of the study, a cross-sectional survey design was considered. Data was collected from four Universities namely Adama Science and Technology University, Addis Ababa Science and Technology University, Addis Ababa University, and Madda Walabu University. The universities were purposefully selected from various generations and sizes of universities.

\section{Population, sampling procedures and sample}

The target population of this study has been university students of regular program of both sexes from different ethnic backgrounds of Addis Ababa Science and Technology, Madda Walabu, Adama Science and Technology and Addis Ababa universities. The total population of the study during the study period was 47, 150. For this study, the combinations of multistage cluster sampling, stratified simple random sampling, simple random sampling and purposive sampling procedures were employed to select respondents. The survey has used the single population proportion formula to determine the sample size.

In order to address non-responses, the sample size had increased by a non-response insurance factor. Thus, allowances of $10 \%$ non-response rate make a total sample of 421 . Furthermore, the single population proportion formula is valid only for simple random or systematic random sampling method; but the sampling technique that is used for this study is multistage cluster sampling technique. Therefore, the calculated sample size has to be multiplied by $\mathrm{D}$ which is the design effect resulting with $\mathrm{N}=$ Dn where $\mathrm{N}$ is the sample size for cluster sample, $\mathrm{n}$ is the sample size obtained from the calculation and D is the design effect. The design effect (D) provides a correction for the loss of sampling efficiency resulting from the use of multi stage cluster sampling instead of simple random sampling. Hence, by considering the design effect of 2 the number had been multiplied by 2 and the total number of students taken for the study was 842 .

\section{Instruments for the study}

To achieve the objectives of this study, the required and relevant information was gathered through questionnaire and interviews. The Amharic and English versions of the questionnaire were extensively used and preferred to other tools for its simplicity for such large sample size and for the nature of the study.

\section{Questionnaire preparation, validation process, and data gathering procedures}

The adapted measuring scale was Intercultural Sensitivity Scale was prepared and presented by the investigator. During the adaptation process of the measuring scale, to secure the psychometric properties (the validity \& reliability) of the scale a standard procedure known as "Steps (Stages) of Instrument Preparation" (Leplege \& Verdier, 1998 cited in Beaton, Guillemin, \& Ferraz, 2000) and which is internationally recognized for its numerous applications was employed.

The intercultural sensitivity items were those of Chen and Starosta's (2000) Intercultural Sensitivity Scale. The original scale contains 24 five-point Likert items with nine items to be reverse scored. The ICSS scale has been intended to measure individuals' feelings about interacting with people who have different cultural backgrounds. The scale includes five sub-scales: interaction engagement, respect for cultural differences, interaction confidence, interaction enjoyment, and interaction attentiveness. The 24 statements include "I enjoy interacting with people from different cultures," "I respect the values of people from different cultures," and "I am open minded to people from different cultures." The alpha reliability coefficient of the original scale was 0.83 . 
In this study before the intercultural sensitivity scale was handed out to the respondents, 3 items were dropped and some modifications were made by the evaluators and experts. Finally, the participants have designated their reaction on the 21 items. Upon their response, item reliability analysis was executed. The internal consistency of the scale on the main study was $\alpha=.802$. The Cronbach's alpha score on this scale was supposed to be high. The pilot study was conducted in Madda Walabu University on 50 Male and Female regular undergraduate students which were not included in the main study.

In data collection, eight data collectors (two from each university) who have previous experience in data collection were recruited. Training was given on the questionnaire and data collection techniques. Data collectors had distributed the questionnaire to the students, remained in the classroom during administration and transported the completed questionnaire from the universities.

Procedurally, both the Amharic and English versions of the same questionnaire were given to the respondents and invited to fill out the one they prefer. The average response rate for this study was $92 \%$, with highest response rate $(100 \%)$ from MWU and lowest response rate $(86 \%)$ from Adama Science and Technology University.

\section{Methods of data analyses}

After the responses on the questionnaires have been collected, SPSS version 21.0 was used to enter, clean, and analyze the collected data. Answer sheets were excluded from entry if respondents failed to complete at least half of the questionnaire. To answer the research questions, descriptive statistics (the mean, SD, variance, quartile and percentile scores), frequency percentages, Chi-square $(\chi 2)$, pairwise chi-square comparisons, independent t-test and one-way ANOVA were computed. Confidence intervals of $95 \%$ were used to see the precision of the study.

\section{Results and Discussions}

Socio-demographic Context of Participants of the Study

Before turning to the foremost analyses of the study, the main socio-demographic characteristics of the respondents are summarized below in Table 1.

Table 1: Socio-demographic Characteristics of Participants of the Study

\begin{tabular}{|c|c|c|c|}
\hline Variables & & Frequency & Percent \\
\hline $\operatorname{Sex}(n=771)$ & $\begin{array}{l}\text { Male } \\
\text { Female }\end{array}$ & $\begin{array}{l}484 \\
287\end{array}$ & $\begin{array}{l}62.8 \\
37.2\end{array}$ \\
\hline Age $(n=765)$ & $\begin{array}{l}18-21 \\
22-25 \\
26 \& \text { above }\end{array}$ & $\begin{array}{l}430 \\
243 \\
92\end{array}$ & $\begin{array}{l}55.8 \\
31.5 \\
11.9\end{array}$ \\
\hline Ethnicity $(n=771)$ & $\begin{array}{l}\text { Oromo } \\
\text { Amhara } \\
\text { Tigrie } \\
\text { SNNP } \\
\text { Somali } \\
\text { Others } \\
\text { Not Identified }\end{array}$ & $\begin{array}{l}202 \\
239 \\
76 \\
108 \\
10 \\
12 \\
124\end{array}$ & $\begin{array}{l}26.0 \\
31.0 \\
9.9 \\
14.0 \\
1.3 \\
1.6 \\
16.1\end{array}$ \\
\hline Ethnic background(n=761) & $\begin{array}{l}\text { Single(mono) } \\
\text { Mixed }\end{array}$ & $\begin{array}{l}456 \\
305\end{array}$ & $\begin{array}{l}59.1 \\
39.6\end{array}$ \\
\hline Religion $(n=765)$ & $\begin{array}{l}\text { Orthodox Christian } \\
\text { Muslim } \\
\text { Protestant } \\
\text { Catholic } \\
\text { Others } \\
\text { Non-religious } \\
\end{array}$ & $\begin{array}{l}465 \\
102 \\
154 \\
12 \\
20 \\
12 \\
\end{array}$ & $\begin{array}{l}60.3 \\
13.2 \\
20.0 \\
1.6 \\
2.6 \\
1.6 \\
\end{array}$ \\
\hline Place grown up $(n=769)$ & $\begin{array}{l}\text { Rural } \\
\text { Urban }\end{array}$ & $\begin{array}{l}255 \\
514\end{array}$ & $\begin{array}{l}33.1 \\
66.7\end{array}$ \\
\hline Year in the University $(n=771)$ & $\begin{array}{l}\text { First Year } \\
\text { Second Year } \\
\text { Third Year } \\
\text { Fourth year and above }\end{array}$ & $\begin{array}{l}182 \\
142 \\
212 \\
235\end{array}$ & $\begin{array}{l}23.6 \\
18.4 \\
27.5 \\
30.5\end{array}$ \\
\hline
\end{tabular}

As indicated in Table 1, a total of 771 regular undergraduate university students have been included from four government universities. The sex distribution of participants was: $484(62.8 \%)$ male and $287(37.2 \%)$ female. The age of the participants ranges 17 to 36 (a mean age of 19.23 years). The majority of students, 430 
$(55.8 \%)$ were in between 18 to 21 years old and the remaining $243(31.5 \%)$ and $92(11.9 \%)$ of them were found between 22-25 and $26 \&$ above years old respectively. As it is indicated in the above table, $456(59.1 \%)$ of the respondents said they are from single (mono) ethnic background whereas $305(39.6 \%)$ of them said they are from mixed ethnic group i.e. their parents were from different ethnic background.

Two hundred two $(26 \%)$ of the respondents identified themselves as Oromo ethnic group whereas 239 $(31.0 \%)$ of them were belongs to Amhara ethnic group. Furthermore, $108(14 \%)$ and $76(9.9 \%)$ were belongs to SNNP and Tigray ethnic groups respectively. Considerable number of respondents, 124 (16.1\%) were not or didn't like to identify their particular ethnic group.

From the total sample, $465(60.3 \%)$ of them were belonged to Orthodox Christians while Protestants and Muslims constitutes $154(20.0 \%)$ and $102(13.2 \%)$ of the total respondents respectively. Others religions mentioned were Catholic $12(1.6 \%)$ and some minor churches $20(2.6 \%)$, while only a few of $12(1.6 \%)$ stated to have no religious affiliations at all.

Five hundred fourteen $(66.7 \%)$ of the respondents identified themselves as they are affiliated to urban background whereas $255(33.1 \%)$ of them were from rural. There was somehow similar distribution across batches (years in university). One hundred eighty two (23.6\%) of them were freshmen, $142(18.4 \%)$ of them were second year and $212(27.5 \%)$ were third year while the remaining $235(30.5 \%)$ were fourth year and above.

\section{Status of Intercultural Sensitivity}

One of the major intents of this study was to determine the intercultural sensitivity status of university students. Hence, in the next sub-section and Table 2, display a descriptive summary of the rating scores of respondents using mean, variances, SD and percentile scores and its description to suggest on the intercultural sensitivity status of university students.

Hence, in order to determine the intercultural sensitivity; percentile scores was utilized to determine the cutoff scores for the different categories. The mean scores on normal curve below $25^{\text {th }}$ percentile score stand for low status, while the mean scores above $75^{\text {th }}$ percentile scores signify the highest status. The mean scores between the $25^{\text {th }}$ and $75^{\text {th }}$ percentile scores denotes medium level of intercultural sensitivity.

Table 2: Descriptive Statistical Values on Intercultural Sensitivity Score

\begin{tabular}{|c|c|c|c|c|c|c|c|c|c|}
\hline & No of & & & \multirow{2}{*}{ SD } & Max & Min & \multicolumn{3}{|c|}{ Percentile Scores } \\
\cline { 4 - 9 } & items & Mean & Variance & & & & $\mathbf{5 0}^{\text {th }}$ & $\mathbf{7 5}^{\text {th }}$ \\
\hline $\begin{array}{c}\text { Intercultural } \\
\text { Sensitivity }\end{array}$ & 14 & 57.52 & 67.53 & 8.22 & 70.00 & 18.00 & 53.00 & 59.00 & 64.00 \\
\hline
\end{tabular}

The descriptive summary of the observed mean score of intercultural sensitivity of minimum scores (1x items 14$)=14$, stands for lowest intercultural sensitivity. Similarly, the average scores for intercultural sensitivity rating scores is $(3 \times 14$ items $)=42$ stands for middle level intercultural sensitivity. Whilst the highest $(5 \times$ items 14$)$ $=70$, expected scores on intercultural sensitivity suggests for the highest status of intercultural sensitivity of university students.

Cognizant of the above assertions, the descriptive summary of the observed mean score $(\mathrm{M}=57.52)$ on intercultural sensitivity rating scale shown in Table 2, is far well above the expected average (42). It is conspicuous that even the lowest $25^{\text {th }}$ percentile score (53.00) is bigger than the expected average (42). As an aftermath, surprisingly 90 percent of the cases, the observed scores are well above the expected average score. These figures may hint that the university students involved in this study has labelled at higher status of intercultural sensitivity. In general, this suggest that respondents are likely sensitive to others culture and each other's.

Furthermore to verify the above information, in other sayings based on the total rating scores on intercultural sensitivity scale, it is possible to label the intercultural sensitivity status of participants of the study into higher, middle and lower level by using the total scores exhibited. And subsequently it is possible to assign the participants to one of the three aforementioned orientations. Relying on the rating scores of respondents (who said strongly disagree and disagree) on intercultural sensitivity scale, the lower score 14-28 stands for lower level of intercultural sensitivity of university students. Similarly, the expected middle scores (scores between disagree and agree) intercultural sensitivity (29-55) on scale stands for middle level of intercultural sensitivity of university students. Whilst the higher (who said agree and strongly agree) expected score 56-70 on intercultural sensitivity scale suggests for the higher level of intercultural sensitivity of university students. 
Table 3: Descriptive Frequency, Chi-square and Pairwise Chi-square Comparisons on Intercultural Sensitivity Score across Different Levels

\begin{tabular}{|c|c|c|c|c|c|c|c|c|c|}
\hline \multirow[t]{2}{*}{ Variable } & \multirow[t]{2}{*}{ Levels } & \multirow[t]{2}{*}{ Freq. } & \multirow[t]{2}{*}{ Percent } & \multirow[t]{2}{*}{ df } & \multirow[t]{2}{*}{$\chi^{2}$} & \multicolumn{4}{|c|}{$\chi^{2}$ (Pairwise Comparisons) } \\
\hline & & & & & & (I) Level & (J) Level & df & $\chi^{2}$ \\
\hline \multirow{5}{*}{$\begin{array}{c}\text { Intercultural } \\
\text { Sensitivity }\end{array}$} & Lower (14-28) & 10 & 1.3 & \multirow{5}{*}{2} & \multirow{5}{*}{$451.10 *$} & Lower & Middle & 1 & $241.43 *$ \\
\hline & \multirow{2}{*}{ Middle (29-55) } & \multirow[t]{2}{*}{270} & \multirow[t]{2}{*}{35} & & & & & & \\
\hline & & & & & & \multirow[t]{2}{*}{ Middle } & \multirow[t]{2}{*}{ Higher } & \multirow[t]{2}{*}{1} & \multirow[t]{2}{*}{$64.18 *$} \\
\hline & Higher $(56-70)$ & 491 & 63.7 & & & & & & \\
\hline & Total & 771 & 100 & & & Higher & Lower & 1 & $461.80 *$ \\
\hline
\end{tabular}

Note: $* P<0.05$

Taking into account the above descriptions, as shown in Table 3, significant number of participants of the study $63.7 \%(\chi 2=451.105, \mathrm{p}<0.05)$ were labelled at higher level of intercultural sensitivity.

Furthermore as indicated in Table 3, pairwise comparisons were conducted among the frequencies on different levels of intercultural sensitivity. The pairwise ad hoc analyses for all comparisons revealed significant differences among the three levels of the variables.

Thus, all the above descriptions may suggest that university students who participated in the study are sensitive to others culture or sensitive to each other's. Consistent to this study a local study by Habtamu, Hallahmi \& Abbink (2001) investigated that good and positive relationship has been exhibited among various ethnic groups' young adult college and high school students in Ethiopia. While the findings of Demewoz that conducted in Addis Ababa University and Dilla College of Teachers Education and Health Sciences of Debub University among four major ethnic groups of students (Amhara, Oromo, Tigre, and Guragie ) reported that all the ethnic group students were ethnocentric (Demewoz, 2001).

Actually, the above mentioned studies are conducted on few segments of "the dominant ethnic groups" in the country such as Amhara, Oromo, Tigre and Guragie. In addition, some of the studies are carried out on few individuals through qualitative methods of inquiry.

\section{Group Differences on Intercultural Sensitivity Scores}

One of the major objectives of this study is to investigate whether there is a significant group difference in intercultural sensitivity score among university students across respondents' sex, ethnic background, place grown up and age. Accordingly to verify this independent t-test analysis, one-way ANOVA and mean comparisons were performed and results obtained from group comparisons are presented as follows:

\section{Sex Difference in Intercultural Sensitivity among University Students}

Table 4: - Sex Difference in Intercultural Sensitivity among University Students (Independent T-Test)

\begin{tabular}{|c|c|c|c|c|c|c|c|}
\hline Dependent Variables & Sex & N & Mean & SD & df & t- obtained & Sig. \\
\hline Intercultural Sensitivity & $\mathrm{M}$ & 484 & 56.95 & 8.16 & & \multirow{2}{*}{} & \multirow{2}{*}{0.013} \\
\cline { 2 - 8 } & $\mathrm{F}$ & 287 & 58.47 & 8.24 & 769 & -2.48 & 0.28 \\
\hline
\end{tabular}

Results shown in Table 4, an independent-samples t-test was conducted to compare the intercultural sensitivity scores for males and females. There was significant mean difference in scores for males $(M=56.96$, $S D=8.16)$ and females $[M=58.47, S D=8.24 ; t(769)=-2.48, p=.013]$. This indicates that female university students are more interculturally sensitive than males. This may suggest that female university students are sensitive to others culture or ethnicity. As argued by (Egan, 2001), gender has its own effect on intercultural sensitivity and social interactions and is consistent to the current finding.

Ethnic Background Difference in Intercultural Sensitivity among University Students Table 5: - Ethnic Background Difference in Intercultural Sensitivity among University Students (Independent T-Test)

\begin{tabular}{|c|c|c|c|c|c|c|c|}
\hline Dependent Variables & Ethnic Background & $\mathrm{N}$ & Mean & SD & df & t- obtained & Sig. \\
\hline \multirow{2}{*}{ Intercultural Sensitivity } & Mono & 456 & 57.30 & 7.91 & & & \\
\cline { 2 - 9 } & Mixed & 305 & 57.87 & 8.66 & 759 & .93 & \multirow{2}{*}{.351} \\
\hline
\end{tabular}

Results depicted in Table 5, reveals that there was no significant differences are observed between single/mono $(M=57.30, S D=7.91)$ and mixed ethnic background $(M=57.87, S D=8.66)$ on intercultural sensitivity score, $t(759)=-.93, p=.351$. Thus, this result would suggest that university students in Ethiopia from single/mono and mixed ethnic background have no difference in their intercultural sensitivity. These results are not supported by findings of Stephan \& Stephen (1991) that "there are some positive effects of bicultural socialization in terms of insulation from the ethnocentrism of single - heritage groups" (p. 248). This might be because of that dual heritage multiethnic (mixed ethnic) increases the likelihood that they will have a close contact with at least two cultures, these individuals may function as a bridge between the groups. Even mixed ethnic individuals who live 
in a monoethnic community and consider themselves to be members of one ethnic group are probably less ethnocentric than monoethnic individuals. People who identify with and participate in two cultures may further the appreciation of diversity and reduction of interethnic intergroup conflicts (Phinney \& Alipuria, 1996; Stephan \& Stephen, 1991).

Residential Background Difference in Intercultural Sensitivity among University Students Table 6: - Residential Background Difference in Intercultural Sensitivity among University Students (Independent T-Test)

\begin{tabular}{|c|c|c|c|c|c|c|c|}
\hline Dependent Variables & Residential Background & $\mathrm{N}$ & Mean & SD & df & t- obtained & Sig. \\
\hline \multirow{2}{*}{ Intercultural Sensitivity } & Rural & 255 & 56.61 & 8.20 & & & \\
\cline { 2 - 6 } & Urban & 514 & 58.01 & 8.19 & 767 & -2.231 & .026 \\
\hline
\end{tabular}

Furthermore to verify whether there is significant difference between urban and rural background university students on intercultural sensitivity an independent t-test result and mean scores displayed in Table 6, there is a statistically significant difference between rural and urban background students rural $(M=56.61, S D=8.20)$ and females $[M=58.01, S D=8.19 ; t(767)=-2.231, p=.026]$. Thus, the results imply that urban university students are better in their intercultural sensitivity than rural background university students.

In the present study, it is evident that data on ethnic composition of urban background university indicate that from the total $305(39.6 \%)$ of the participants drawn from mixed ethnic group, 249 (82\%) of them are urban background. This may hint that the majority urban background university students were mixed in their ethnicity. People who identify with and participate in two cultures are better in appreciation of diversity and reduction of interethnic and intergroup conflicts (Phinney \& Alipuria, 1996).

Intercultural Sensitivity among University Students across different Batches

This study also determined whether years of stay in university has made a difference on intercultural sensitivity scores among students; one-way ANOVA has been employed and is presented below.

Table 7: - Summary Table of one-way ANOVA

\begin{tabular}{|l|r|r|r|r|r|}
\hline & Sum of Squares & \multicolumn{1}{c|}{ df } & Mean Square & \multicolumn{1}{c|}{ F } & Sig. \\
\hline Between Groups & 1570.608 & 3 & 523.536 & 7.963 & .000 \\
Within Groups & 50425.869 & 767 & 65.744 & & \\
Total & 51996.477 & 770 & & & \\
\hline
\end{tabular}

ANOVA test indicated in Table 7, reveal that there is significant differences across batches on intercultural sensitivity score, $\mathrm{F}(3,767)=7.963, \mathrm{P}=.000$. An examination of the mean scores unveiled that second year university students exhibited higher on intercultural sensitivity scale $(M=59.32, S D=7.71)$ than the other batches particularly from freshmen students $(M=55.13, S D=8.16)$ and third year $(M=57.92, S D=7.92)$, fourth year and above $(M=57.92, S D=8.21)$.

In addition to an analysis of one-way ANOVA above, mean comparison Post hoc analysis of Tukey's procedure were performed for the significant differences among different batches have been exhibited. For intercultural sensitivity the difference between the second and the rest is ascribed for the differences. In general, the results of these analyses provide that second year university students are better in their intercultural sensitivity than other batches. This may suggest that students' duration of stay in the university has an impact on the sensitivity of university students towards each other and in handling interethnic conflicts. However, freshmen students may busy with searching for their ethnic identity and attached to inner group than outer group than senior class students.

\section{Conclusion}

Several individuals and studies deemed higher learning institutions (universities) in Ethiopia are centers of unrest and unhealthy relationships (Abera H., 2010; Abera T., 2010; Asefa, 2009) and ethnocentrism (Demewoz, 2001; 1997) among some section of university students especially between the dominant ethnic groups such as Oromo, Amhara, Tigrie and Guragie. On the contrary, others have asserted that exposure to university programs may offer an opportunity for intellectual framework for understanding the historical, psychological, and sociological foundations of multiculturalism.

The findings of the study, disclose that higher intercultural sensitivity status observed among the participants of university students. This may suggest that university students who took part in this study are likely sensitive to others culture. This may hint that respondents of the university students do not exhibit a tendency of ethnocentric attitude and behaviour.

There was significant mean difference in mean scores for males and females on intercultural sensitive score. The result indicates that female university students are more interculturally sensitive than males. Whereas, ANOVA tests provide non-significant differences between single/mono and mixed ethnic background on 
intercultural sensitivity score. Similarly the study provides clear evidence of the variability of on intercultural sensitive score between rural and urban background university students. Urban background university students scored slightly higher than rural background students on intercultural sensitivity scale. Furthermore, second year students exhibited higher on intercultural sensitivity scale than other batches particularly from freshmen students. Practical Implications

Based on the major findings and the conclusions drawn, the following practical implications, suggestions and recommendations are implied to be taken into account by line stakeholders: The evidence provides herein this study healthier feeling, attitudes and behaviours (higher intercultural sensitivity). Thus, the findings of this study would help policy makers, university administrators and others in their efforts to bring about mutual understanding and more positive relationships among various ethnic group university students in Ethiopia.

\section{Limitations}

The limitation of this study is that the participants of the study were considered from four universities of undergraduate students. As a consequence, findings must be reviewed with some measure of caution because the private universities and other higher education institutions (TVET and Teachers' Colleges) were not considered.

\section{References}

Abera, H. M. (2010). Ethnic identity and the relations of Amhara, Ormo and Tigray students at Addis Ababa University main campus (MA Thesis). In F. E. Stiftung, An Anthology of Peace and Security Research (pp. 1-67). Addis Ababa: Addis Ababa University Institute for Peace and Security Studies.

Abera, T. (2010). The influence of inter-ethnic attitude on inter-ethnic quality of interaction among AAU main campus Oromo, Amhara and Tigray students. Addis Ababa: Unpublished MA Thesis.

Asebe, R. (2007). Ethnicity and interethnic relations: the 'Ethiopian experiment' and the case of the Guji and Gedeo. University of Tromso: Unpublished MA thesis submitted for the Faculty of Social Sciences.

Asefa, J. (1998). Oromo nationalism and the Ethiopian discourse. Lawrenceville NJ: The Red Sea Press.

Beaton, D. E., Guillemin, F., \& Ferraz, B. M. (2000). Guidelines for the process of cross-cultural adaptation of self-report measures. Retrieved March 2013, from www.problemsinanes.com/.../fulltext.00007632200012150-00014.0.

Bennett, M. (1986). A developmental approach to training for intercultural sensitivity. International Journal of Intercultural Relations , 10, 179-196.

Bennett, M. J. (1998). Intercultural communication: A current perspective. In M. J. Bennett, Basic concepts of intercultural communication: Selected readings (pp. 1-34). Yarmouth, ME: Intercultural Press.

Bennett, M. (1993). Towards ethnorelativism: A developmental model of intercultural sensitivity. In R. M. Paige, Education for the Intercultural Experience (pp. 123-188). Yarmouth, ME: Intercultural Press.

Blum, L. (2010). Rethinking the role of the modern university. In E. Kiss, \& P. Euben, Debating Moral Education. London: Duke University Press.

Chen, G. M. (2010). The impact of intercultural sensitivity on ethnocentrism and intercultural communication apprehension. Intercultural Communication Studies, 19(1), 1-9.

Chen, G. M., \& Starosta, W. J. (2000). The development and validation of the international communication sensitivity scale. Human Communication , 3, 2-14.

Chen, G. M., \& Strosta, W. J. (2003). Intercultural awareness. In A. S. L, \& R. E. Porter, Intercultural communication: A reader (10th ed.) (pp. 344-353). Belmont, CA: Wadsworth/Thomson Learning.

CSA. (2008). Population and housing census of Ethiopia: Country Level. Addis Ababa.

Demewoz, A. (2001). Ethnocentrism among four ethnic groups of students; implications and future direction: the case of Dilla College of Teacher Education and Health Sciences. Conflict in the Horn: Prevention and Resolution (pp. 25-28). Addis Ababa: OSSREA.

Egan, S. K. (2001). Gender identity: A multidimensional analysis with implications for psychosocial adjustment. Developmental Psychology, 37(4), 451-463.

FDRE. (2009, September 17th). Higher Education Proclamation NO. 650/2009. Federal Negarit Gazeta, pp. 4976-5044.

Fleiner, L. R. (2000). Can ethnic federalism work?' Paper for the conference on "facing ethnic conflicts". Bonn, Germany 14-16, December 2000: Center for Development Research (ZEF Bonn).

Habtamu, W., Hallahmi, B. B., \& Abbink, J. (2001). Psychological modernity and attitudes to social change in Ethiopian young adults: The role of ethnic identity and stereotypes. NIRP Research for Policy Series 9, Royal Tropical Institute KIT Publisher.

Lubo, T. (2012). The post 1991 'inter-ethnic' conflicts in Ethiopia: An investigation. Journal of Law and Conflict Resolution , 4(4), 62-69.

Pascarella, E. T., \& Terenzini, P. T. (1991). How college affects students. San Francisco: Jossey-Bass.

Phinney, J., \& Alipuria, L. (1996). At the interface of culture: Multiethnic/multiracial high school and college 
students. Journal of Social Psychology , 136, 139-158.

Stephan, W. G., \& Stephan, C. W. (1991). Intermerriage: Effects on personality, adjustement, and intergroup relations in two samples of students. Journal of Marriage and the Family, 53(1), 241- 250.

Strauss, A., \& Corbin, J. (1990). Basics of qualitative research: Grounded theory procedures and techniques. Newbury Park, CA: Sage.

Tilahun, B. (2007). Management of on group conflicts among students of diversebackground: A multicultural perspective the case of Bahr Dar University. Addis Ababa: Addis Ababa University unpublished MA thesis.

Vaughan, S. (2003). Ethnicity and power in Ethiopia. Edinburgh: The University of Edinburgh, PhD Dissertation . 